Proceedings

\title{
Extended-Family Talk about Sex and Teen Sexual Behavior $^{+}$
}

\author{
Jennifer M. Grossman ${ }^{1, *}$, Alicia D. Lynch ${ }^{2}$, Amanda M. Richer ${ }^{1}$ and Lisette M. DeSouza ${ }^{1}$ \\ 1 Wellesley College, 106 Central Street, Wellesley, MA 02481, USA; aricher@wellesley.edu (A.M.R.); \\ ldesouza@wellesley.edu (L.M.D.) \\ 2 Lynch Research Associates, 1 South Avenue, Natick, MA 01760, USA; aliciadlynch@gmail.com \\ * Correspondence: jgrossma@wellesley.edu \\ + Presented at the 1st International Electronic Conference on Environmental Health Sciences, \\ 15 November-7 December 2018; Available online: https://iecehs-1.sciforum.net/.
}

Published: 14 November 2018

\begin{abstract}
Research shows that family sexuality communication is protective for teens' risky sexual behavior, but most studies on this topic focus exclusively on the parent-teen dyad. The few studies that assessed extended family sexuality communication use a single item to measure this communication and showed mixed results as to whether it is associated with sexual risk behaviors for teens. The current study included cross-sectional survey data from 952 teens in the 11th and 12th grades. Structural equation modeling (SEM) was used to assess associations between teens' sexual risk behaviors and communication with extended family about protection methods, risks of sex and relational approaches to sex. Results showed that, for sexually active teens, talk about protection methods was associated with fewer sexual partners and talk about risks of sex was associated with more sexual partners, even after accounting for talk with parents about sex and controlling for teen gender, racial/ethnic background and mothers' education. Results suggest that extended family talk with teens about sex might protect them from risky sexual behavior, over and above the effects of teen-parent communication. However, the direction of the effect depends on the content of the conversations. Talk about protection might support teens' sexual health, while talk about risks of sex with teens who have already had sex, might not be effective. These findings suggest the need to explore whether and how extended family could be included in health prevention and intervention programs, which currently focus on parents.
\end{abstract}

Keywords: adolescent reproductive health; family communication; extended family; teen sexual behavior

\section{Introduction}

Risky sexual behaviors, such as early sex and lack of protection, leave teens vulnerable to sexually transmitted infections (STIs) and unplanned pregnancy [1]. Research shows that family sexuality communication is protective for risky sexual behavior [2,3], but most studies on this topic focus exclusively on the parent-teen dyad [4]. This focus ignores the findings that over half of teens talk with extended family about sex or relationships [5]. Preliminary quantitative research showed significant associations between the extended-family's sexuality communication and teen sexual beliefs and behavior [5,6]. However, existing research often uses a single item to assess extendedfamily sexuality communication $[7,8]$, and does not examine under what conditions the extended family sexuality communication is protective or risk-promoting. Using a more comprehensive measure of the extended family's communication, the current study extended the extant research by assessing the associations between communication and teens' sexual risk behaviors, and whether 
these associations differ, based on the generation of the family members (i.e., grandparents, uncles/aunts, cousins) that the teen talks to and the teen's gender. We defined extended family to include aunts, uncles, grandparents, older cousins, older siblings, and godparents. We included siblings because research suggests commonalities between teens' sexuality communication with siblings and cousins $[9,10]$.

Communication with extended family might be particularly important as teens become sexually active. At this stage, teens might become reluctant to talk to their parents about sexual issues, as they fear their parents might judge them or worry about their sexual behaviors [11,12]. Hence, some teens seek out extended family as a more comfortable alternative to parents [10]. In addition, parents often focus their messages to teens on delaying sex [13], which can be protective before teens become sexually active [14], but might be less effective when teens have already had sex. Extended family might be more open to discussing protection methods with teens, rather than only focusing on messages to delay sex [13]. Therefore, it is important to investigate extended family sexuality communication and teens' safer sex practices (e.g., condom use, number of partners) among teens who are sexually active, rather than a sole focus on the teens' transition to sex.

A better understanding of the effects of family sexuality communication on teens' sexual behavior can be gained by assessing who the teen talks to and the teen's gender. Whether messages about sex are protective might depend on which extended family member the teen talks to. For example, findings are mixed as to whether older siblings positively or negatively influence younger siblings' sexual behavior [15-17], while talking with grandmothers about sex and relationships has shown associations with healthy teen sexual behavior [6,18]. Teens' gender also shapes family sexuality communication. Findings are mixed regarding whether the impact of this family sexuality communication differs for girls and boys [4,19]. Research is needed to assess whether the effects of the extended family sexuality communication differ depending on the generation of the extended family member (e.g., parents' versus teens' generation) and the teen's gender.

The current study assesses (1) associations of extended family sexuality communication with the teens' sexual behaviors, and (2) whether this communication differs by the generation of extended family (same generation as the teen vs. parents' generation vs. grandparents' generation) and the gender of the teen. We hypothesize that the extended-family communication about protection will be negatively associated with participants' safer sex behaviors, while communication about the dangers of sex will not be associated with participants' safer sex behaviors. We do not expect that extended family sexuality communication will be associated with delay of sex. Analyses assessing whether effects of communication differ by the extended-family generation and teen gender are exploratory.

\section{Methods}

Data for this study was obtained from 11th and 12th grade students at six urban schools. Schools were recruited through school and district offices. Each school was assigned a study liaison responsible for data collection coordination, and was paid a $\$ 500$ stipend for participation. The study was approved by the Wellesley College Institutional Review Board. A survey was administered online, using Qualtrics. Four of the six participating schools selected the waiver of documentation of parental consent ("passive consent"), while two schools selected active consent. A total of 973 surveys were collected, of which 952 are included in this analysis, following data cleaning procedures.

\subsection{Sample}

Participants were 952 adolescents (Mage $=17.02, \mathrm{SD}=0.93$ ), and self-identified as $55 \%$ female, $17 \%$ Black, 54\% Latino, 16\% White, 7\% Asian, 4\% Middle Eastern, and 2\% Biracial/Multiracial. On average, mothers of participants (or primary caregivers) had a high school education, and $71 \%$ of these mothers immigrated to the U.S. Thirty-five percent of adolescents reported having vaginal sex. Almost half of participants (48\%) reported talking to at least one parent or an extended family member (46\%) about dating, sex, and relationships. The extended family members who the teens primarily reported talking to were-older sisters (24\%) and older female cousins (21\%). Older 
brothers $(16 \%)$, aunts $(13 \%)$, and older male cousins $(10 \%)$ were also reported as communication partners. Fewer adolescents reported talking to grandmothers $(7 \%)$, uncles $(6 \%)$, grandfathers $(1 \%)$, and godparents (1\%).

\subsection{Measures}

The Direct communication measure consisted of three sub-scales. Protection communication was made up of three items asking whether the teens had engaged in conversations with family members about protecting themselves from STIs, HIV/AIDS, and from becoming pregnant or getting someone else pregnant $(\alpha=0.93)$. Risks of Sex communication had four items, asking about conversations concerning the negative consequences of sex, including teen pregnancy and STDs. $(\alpha$ $=0.86$ ). Relational Sex communication included three items, addressing how sex can be permissible, in the context of a relationship $(\alpha=0.87)$.

Generation of extended family consisted of three levels. The younger generation included older siblings and cousins, the middle generation family members included aunts/uncles and godparents, and the older generation included grandparents.

Control variables consisted of - teens' gender, age, race/ethnicity, whether they live in a twoparent household, and teens' religiosity. Teens were also asked about their mothers' education, whether their parents were immigrants, and whether either of their parents was a teen parent. Communication with parents about dating and sex was measured by the teens' self-report of talking with at least one parent about these topics.

Sexual behavior outcomes included - vaginal sex, number of sexual partners, and condoms use. If the teen did not report having sex, they were assigned a zero, for the number of partners.

\subsection{Analysis}

First, separate Structural Equation Models (SEM) were used to test the relationships among direct sex communication with extended family members and each of the three youth sexual behavior outcomes (vaginal sex, condom use, and number of partners). Next, in separate SEMs, we examined whether youth gender and the generation of the extended family member, moderated the link between direct sex communication and youth sexual behavior. Each SEM comprised a measurement model and a structural model. The measurement model contained the three direct communication scales (Protection, Risks of Sex, and Relational Sex), represented as separate latent variables. In the structural model, each of the observed exogenous variables and the three latent variables representing direct sex communication, were regressed on the endogenous variable representing youth sexual behavior. In the moderation models, additional latent variables, representing each moderating effect, were also regressed onto the endogenous variable. Control variables (described above) were included. Given that vaginal sex was measured dichotomously, model parameters were generated using a diagonally weighted least squares estimator (WLSMV) and pairwise estimation of the missing data. For the models predicting youth condom use and the number of sexual partners, full information maximum likelihood (FIML) was used. All analyses were conducted in the Lavaan package (version 0.6-3) in R [20].

\section{Results and Discussion}

Model fit statistics suggested an excellent fit for all of the SEMs tested. Specifically, Tucker-Lewis Indices (TLI) ranged from 0.95-0.98, Comparative Fit Indices (CFI) from 0.94-0.96, and root mean square error of approximation (RMSEA) from 0.04-0.06. In the models assessing the relationships among direct communication with extended family members and youth sexual outcomes, protection and risk communication were both found to be significant predictors of youths' reported number of sexual partners. These effects went in opposite directions, with communication about protection predicting fewer sexual partners $(\beta=-0.502, \mathrm{SE}=0.164)$ and communication about risks of sex predicting more sexual partners $(\beta=0.656, \mathrm{SE}=0.237)$. Models predicting delay of sex and condom use were not significant (Table 1). 
Table 1. Direct Effects of Extended Family Communication on Teen Sexual Behaviors.

\begin{tabular}{|c|c|c|c|c|c|}
\hline & \multicolumn{2}{|l|}{$\begin{array}{c}\text { Delay Sex } \\
\beta(\mathrm{SE})\end{array}$} & \multirow{2}{*}{$\begin{array}{c}\text { Condom Use } \\
\boldsymbol{\beta} \text { (SE) } \\
-0.28(0.20)\end{array}$} & \multicolumn{2}{|c|}{$\begin{array}{c}\text { Number of Sex Partners } \\
\beta \text { (SE) }\end{array}$} \\
\hline Protection Communication & $0.07(3.92)$ & & & $-0.50(0.16)$ & * \\
\hline Risks of Sex Communication & $0.23(5.93)$ & & $0.36(0.36)$ & $0.66(0.24)$ & * \\
\hline Relational Sex Communication & $-0.14(5.17)$ & & $0.22(0.26)$ & $-0.13(0.17)$ & \\
\hline Female & $-0.09(0.12)$ & & $-0.23(0.22)$ & $0.07(0.16)$ & \\
\hline Age & $0.16(0.07)$ & * & $-0.19(0.13)$ & $0.08(0.10)$ & \\
\hline Mother's Education & $0.04(0.04)$ & & $-0.06(0.07)$ & $0.03(0.05)$ & \\
\hline Teen Parent & $0.35(0.13)$ & ** & $-0.21(0.23)$ & $0.03(0.17)$ & \\
\hline Religion & $-0.04(0.06)$ & & $0.09(0.12)$ & $-0.10(0.08)$ & \\
\hline Parent Immigrant & $-0.21(0.16)$ & & $0.04(0.31)$ & $0.03(0.21)$ & \\
\hline Black & $-0.31(0.21)$ & & $-0.35(0.42)$ & $0.01(0.31)$ & \\
\hline Latino & $0.13(0.18)$ & & $-0.47(0.34)$ & $-0.49(0.24)$ & * \\
\hline Asian & $-0.38(0.27)$ & & $-0.59(0.60)$ & $-0.42(0.43)$ & \\
\hline Biracial/Other & $-0.41(0.30)$ & & $-0.21(0.62)$ & $-0.40(0.41)$ & \\
\hline Two Parent Household & $-0.20(0.13)$ & & $0.04(0.25)$ & $-0.04(0.17)$ & \\
\hline Talk to Parent about Sex & $0.17(0.12)$ & & $0.43(0.25)$ & $0.32(0.17)$ & \\
\hline
\end{tabular}

In the models examining the potential moderating roles of youth gender and generation of the extended family member, there were no significant findings (Table 2). This suggests that the link between direct communication with extended family members about sex and teens' sexual behaviors was stable, regardless of teen gender or the generation of the extended family member with whom the teen was communicating about sex.

Negative associations between communication about protection and the number of partners, and positive associations between the risks of sex communication with the number of partners, confirmed study hypotheses. For sexually active teens, conversations about safer sex were found to fit with the teens' developmental stage and experience, and could encourage them to make thoughtful decisions about their sexual activity. Extended family might take on a larger role for these teens, due to their concerns about parental judgement regarding their sexual behavior [11], and due to the openness among extended family members to discussing safer sex behaviors, compared to parents, who tend to focus on delaying sex [13]. In contrast, extended-family messages about the risks of sex (reasons not to have sex) might strike a dissonant chord with teens who are already sexually active. For this group of teens, messages about delaying sex do not acknowledge their sexual behavior and suggest that sexual behavior is bad or inappropriate, while also failing to provide tools or information to support safer sex behaviors. As hypothesized, extended family sexuality communication was not associated with delay of sex. This might reflect parents' key role in talking with teens about the dangers of sex, which is associated with delayed sex among teens who are not yet sexually active [21]. Contrary to the study hypotheses, extended family sexuality communication did not predict teens' condom use. The lack of significant moderation findings for the generation of the extended family suggested that the protective potential of extended family messages about sex did not depend on the age of the extended family member. This ran counter to findings that samegeneration family members, such as siblings, promote risky sexual behavior among their younger teen relatives [17]. Non-significant moderation findings for teen gender indicated that the effects of extended family messages did not differ for teen boys and girls. 
Table 2. Moderation of Teen Gender and Extended Family Generation on Extended Family Communication and Teen Sexual Behavior.

\begin{tabular}{|c|c|c|c|c|c|c|c|c|c|c|c|c|}
\hline & \multicolumn{6}{|c|}{ Teen Gender Moderation } & \multicolumn{6}{|c|}{ Extended Family Generation Moderation } \\
\hline & Delay Sex & & Condom Use & & $\begin{array}{c}\text { Number of } S \\
\text { Partners }\end{array}$ & & Delay Sex & & Condom Use & & $\begin{array}{c}\text { Number of Sex } \\
\text { Partners }\end{array}$ & \\
\hline & $\beta(\mathrm{SE})$ & & $\beta(\mathrm{SE})$ & & $\beta(\mathrm{SE})$ & & $\beta(\mathrm{SE})$ & & $\beta(\mathrm{SE})$ & & $\beta(\mathrm{SE})$ & \\
\hline Protection Communication & $0.03(4.61)$ & & $-0.05(16.33)$ & & $-0.49(0.17)$ & * & $-0.05(8.70)$ & & $0.12(51.49)$ & & $-0.57(0.31)$ & \\
\hline Risks of Sex Communication & $0.31(8.69)$ & & $0.01(9.63)$ & & $0.73(0.25)$ & * & $0.33(46.78)$ & & $0.35(103.27)$ & & $0.87(0.56)$ & \\
\hline Relational Sex Communication & $-0.15(8.06)$ & & $0.21(19.31)$ & & $-0.22(0.18)$ & & $-0.01(51.13)$ & & $-0.24(67.63)$ & & $-0.06(0.30)$ & \\
\hline Protection X Teen Gender & $-0.02(19.34)$ & & $0.03(19.41)$ & & $-0.25(0.34)$ & & -- & & -- & & -- & \\
\hline Risks of Sex X Teen Gender & $-0.02(45.31)$ & & $0.02(34.14)$ & & $0.09(0.49)$ & & -- & & -- & & -- & \\
\hline Relational Sex X Teen Gender & $-0.08(26.16)$ & & $0.06(20.34)$ & & $0.07(0.40)$ & & -- & & -- & & -- & \\
\hline Protection X Middle Age EF & -- & & -- & & -- & & $0.01(20.55)$ & & $-0.32(25.38)$ & & $0.50(0.71)$ & \\
\hline Risks of Sex X Middle Age EF & -- & & -- & & -- & & $-0.02(136.42)$ & & $0.04(138.25)$ & & $-0.27(1.25)$ & \\
\hline Relational Sex X Middle Age EF & -- & & -- & & -- & & $0.08(125.02)$ & & $0.18(133.22)$ & & $-0.03(0.83)$ & \\
\hline Protection X Older Age EF & -- & & -- & & -- & & $0.03(177.05)$ & & $0.06(90.03)$ & & $-0.50(1.78)$ & \\
\hline Risks of Sex X Older Age EF & -- & & -- & & -- & & $-0.01(472.61)$ & & $0.01(262.55)$ & & $0.77(4.91)$ & \\
\hline Relational Sex X Older Age EF & -- & & -- & & -- & & $-0.01(314.04)$ & & $-0.02(171.28)$ & & $-0.06(1.39)$ & \\
\hline Middle Age EF & & & & & & & $0.12(0.16)$ & & $-0.19(0.25)$ & & $-0.01(0.29)$ & \\
\hline Older Age EF & & & & & & & $-0.13(0.22)$ & & $0.66(0.39)$ & & $-0.65(0.35)$ & \\
\hline Female & $-0.09(0.12)$ & & $-0.17(0.19)$ & & $0.09(0.16)$ & & $-0.13(0.13)$ & & $-0.08(0.23)$ & & $0.10(0.19)$ & \\
\hline Age & $0.16(0.07)$ & * & $-0.15(0.11)$ & & $0.07(0.10)$ & & $0.11(0.09)$ & & $0.06(0.16)$ & & $-0.01(0.12)$ & \\
\hline Mother's Education & $0.04(0.04)$ & & $-0.04(0.06)$ & & $0.03(0.05)$ & & $0.01(0.04)$ & & $0.00(0.07)$ & & $0.01(0.06)$ & \\
\hline Teen Parent & $0.35(0.13)$ & $* *$ & $-0.13(0.19)$ & & $0.04(0.17)$ & & $0.40(0.15)$ & $* *$ & $-0.44(0.22)$ & * & $0.15(0.21)$ & \\
\hline Religion & $-0.04(0.06)$ & & $0.10(0.09)$ & & $-0.11(0.08)$ & & $-0.05(0.07)$ & & $-0.09(0.13)$ & & $-0.06(0.10)$ & \\
\hline Parent Immigrant & $-0.21(0.16)$ & & $0.01(0.25)$ & & $0.05(0.22)$ & & $-0.34(0.20)$ & & $0.41(0.31)$ & & $-0.04(0.28)$ & \\
\hline Black & $-0.31(0.21)$ & & $-0.28(0.36)$ & & $0.01(0.31)$ & & $-0.11(0.25)$ & & $-0.49(0.41)$ & & $0.04(0.38)$ & \\
\hline Latino & $0.13(0.18)$ & & $-0.35(0.25)$ & & $-0.50(0.24)$ & * & $0.27(0.22)$ & & $-0.54(0.32)$ & & $-0.68(0.31)$ & * \\
\hline Asian & $-0.38(0.27)$ & & $-0.30(0.47)$ & & $-0.43(0.43)$ & & $-0.02(0.31)$ & & $-0.89(0.56)$ & & $-0.51(0.51)$ & \\
\hline Biracial/Other & $-0.41(0.30)$ & & $-0.16(0.84)$ & & $-0.40(0.41)$ & & $-0.11(0.34)$ & & $-0.22(1.02)$ & & $-0.87(0.52)$ & \\
\hline Two Parent Household & $-0.20(0.13)$ & & $-0.03(0.19)$ & & $-0.04(0.17)$ & & $-0.23(0.15)$ & & $-0.35(0.23)$ & & $0.07(0.21)$ & \\
\hline Talk to Parent about Sex & $0.17(0.12)$ & & $0.43(0.19)$ & * & $0.27(0.18)$ & & $0.26(0.15)$ & & $0.52(0.25)$ & * & $0.38(0.22)$ & \\
\hline
\end{tabular}




\section{Conclusions}

Close to half of teens talk with extended family about sex [5], yet little research has investigated whether and under what conditions this communication could protect teens from risky sexual behavior. While the current findings are cross-sectional, they suggest that extended family communication might make a difference in teens' sexual behavior. They might play a particularly important role for sexually active teens, who often turn to extended family for less judgmental and more open supports for discussing sexual issues [13]. The content of this communication is critical, as it can be either protective or risk-promoting. As shown in research with parents [22], extended family might underestimate teens sexual behavior and, therefore, share messages about sex that do not match teens' behaviors and their needs for information and support. In contrast, talking with sexually active teens about how to minimize risk might support teens' sexual health. Extended-family communication has similar effects, regardless of the generation of the extended-family that the teen talks with, and the gender of the teen. Overall, these findings suggest that (1) given the frequency and potential health effects of teens' communication with extended family, these relationships should be recognized in teen health programs, which primarily focus on parents [23,24]. Counter to common fears about teens' conversations with siblings and cousins about sex, these preliminary data suggest that programs should not discourage teens from talking with their older siblings and cousins about sex and relationships, particularly when teens do not have a parent they can talk to about these issues. (2) Education is needed to support the extended family members, regarding which type of communication can effectively support the health of sexually active teens. Targeting communication to a teen's development and experience is key to its protective potential.

Acknowledgements: This research was supported by a grant from the Eunice Kennedy Shriver National Institute of Child Health and Human Development (NICHD): R21HD088955. The content is solely the responsibility of the authors and does not necessarily represent the official views of the National Institutes of Health.

\section{References}

1. Centers for Disease Control and Prevention. Youth Risk Behavior Surveillance-United States, 2015. MMWR Morb. Mortal. Wkly. Rep. 2016, 65, 1-74.

2. Murry, V.M.; McNair, L.D.; Myers, S.S.; Chen, Y.-F.; Brody, G.H. Intervention induced changes in perceptions of parenting and risk opportunities among rural African American. J. Child Fam. Stud. 2014, 23, 422-436.

3. Trejos-Castillo, E.; Vazsonyi, A.T. Risky sexual behaviors in first and second generation Hispanic immigrant youth. J. Youth Adolesc. 2009, 38, 719-731, doi:10.1007/s10964-008-9369-5.

4. Widman, L.; Choukas-Bradley, S.; Noar, S.M.; Nesi, J.; Garrett, K. Parent-adolescent sexual communication and adolescent safer sex behavior: A meta-analysis. JAMA Pediatr. 2016, 170, 52-61, doi:10.1001/jamapediatrics.2015.2731.

5. Grossman, J.M.; Tracy, A.J.; Richer, A.M.; Erkut, S. The role of extended family in teen sexual health. J. Adolesc. Res. 2015, 30, 31-56, doi:10.1177/0743558414546718.

6. Bleakley, A.; Hennessy, M.; Fishbein, M.; Jordan, A. How sources of sexual information relate to adolescents' beliefs about sex. Am. J. Health Behav. 2009, 33, 37-48, doi:10.5993/ajhb.33.1.4.

7. Grossman, J.M.; Tracy, A.J.; Richer, A.M.; Erkut, S. Comparing sexuality communication among offspring of teen parents and adult parents: A different role for extended family. Sex. Res. Soc. Policy 2015, doi:10.1007/s13178-015-0183-z.

8. Guzmán, B.L.; Schlehofer-Sutton, M.M.; Villanueva, C.M.; Stritto, M.E.D.; Casad, B.J.; Feria, A. Let's Talk About Sex: How Comfortable Discussions About Sex Impact Teen Sexual Behavior. J. Health Commun. 2003, 8, 583-598, doi:10.1080/716100416.

9. Harper, G.W.; Timmons, A.; Motley, D.N.; Tyler, D.H.; Catania, J.A.; Boyer, C.B.; Dolcini, M.M. ‘It takes a village:' Familial messages regarding dating among African American adolescents. Res. Hum. Dev. 2012, 9, 29-53, doi:10.1080/15427609.2012.654431. 
10. Teitelman, A.M.; Bohinski, J.M.; Boente, A. The social context of sexual health and sexual risk for urban adolescent girls in the United States. Issues Ment. Health Nurs. 2009, 30, 460-469, doi:10.1080/01612840802641735.

11. Crohn, H.M. Communication about sexuality with mothers and stepmothers from the perspective of young adult daughters. J. Divorce Remarriage 2010, 51, 348-365, doi:10.1080/10502551003652108.

12. Guerrero, L.K.; Afifi, W.A. What parents don't know: Topic avoidance in parent-child relationships. In Parents, Children, and Communication: Frontiers of Theory and Research; Socha, T.J., Stamp, G.H., Eds.; Lawrence Erlbaum Associates, Inc.: Hillsdale, NJ, USA, 1995; pp. 219-245.

13. Grossman, J.M.; Richer, A.M.; Charmaraman, L.; Ceder, I.; Erkut, S. Youth Perspectives on Sexuality Communication with Parents and Extended Family. Fam. Relat. 2018, 67, 368-380, doi:10.1111/fare.12313.

14. Bersamin, M.; Todd, M.; Fisher, D.A.; Hill, D.L.; Grube, J.W.; Walker, S. Parenting practices and adolescent sexual behavior: A longitudinal study. J. Marriage Fam. 2008, 70, 97-112, doi:10.1111/j.17413737.2007.00464.x.

15. East, P.L.; Khoo, S.T. Longitudinal pathways linking family factors and sibling relationship qualities to adolescent substance use and sexual risk behaviors. J. Fam. Psychol. 2005, 19, 571-580, doi:10.1037/08933200.19.4.571.

16. Secor-Turner, M.; Sieving, R.E.; Eisenberg, M.E.; Skay, C. Associations between sexually experienced adolescents' sources of information about sex and sexual risk outcomes. Sex Educ. 2011, 11, 489-500, doi:10.1080/14681811.2011.601137.

17. Whiteman, S.D.; Zeiders, K.H.; Killoren, S.E.; Rodriguez, S.A.; Updegraff, K.A. Sibling influence on mexican-origin adolescents' deviant and sexual risk behaviors: The role of sibling modeling. J. Adolesc. Health 2013, doi:10.1016/j.jadohealth.2013.10.004.

18. Cornelius, J.B.; Xiong, P.H. Generational differences in the sexual communication process of African American grandparent and parent caregivers of adolescents. J. Spec. Pediatr. Nurs. 2015, 20, 203-209, doi:10.1111/jspn.12115.

19. Bulat, L.R.; Ajduković, M.; Ajduković, D. The role of parents and peers in understanding female adolescent sexuality-Testing perceived peer norms as mediators between some parental variables and sexuality. Sex Educ. 2016, 16, 455-470, doi:10.1080/14681811.2015.1110691.

20. Rosseel, Y. lavaan: An R Package for Structural Equation Modeling. J. Stat. Softw. 2012, 48, 36, doi:10.18637/jss.v048.i02.

21. Coley, R.L.; Lombardi, C.M.; Lynch, A.D.; Mahalik, J.R.; Sims, J. Sexual partner accumulation from adolescence through early adulthood: The role of family, peer, and school social norms. J. Adolesc. Health 2013, 53, 91-97.

22. Mollborn, S.; Everett, B. Correlates and consequences of parent-teen incongruence in reports of teens' sexual experience. J. Sex Res. 2010, 47, 314-329.

23. Grossman, J.M.; Tracy, A.J.; Charmaraman, L.; Ceder, I.; Erkut, S. Protective Effects of Middle School Comprehensive Sex Education With Family Involvement. J. Sch. Health 2014, 84, 739-747, doi:10.1111/josh.12199.

24. Tortolero, S.R.; Markham, C.M.; Peskin, M.F.; Shegog, R.; Addy, R.C.; Escobar-Chaves, S.L.; Baumler, E.R. It's your game: Keep it real: Delaying sexual behavior with an effective middle school program. J. Adolesc. Health 2010, 46, 169-179, doi:10.1016/j.jadohealth.2009.06.008.

(C) 2018 by the authors. Licensee MDPI, Basel, Switzerland. This article is an open access article distributed under the terms and conditions of the Creative Commons Attribution (CC BY) license (http://creativecommons.org/licenses/by/4.0/). 